\title{
Retraction Note to: Derivative with two fractional orders: A new avenue of investigation toward revolution in fractional calculus
}

\author{
Abdon Atangana ${ }^{\mathrm{a}}$ \\ Institute for Groundwater studies, Faculty of Natural and Agricultural Sciences, University of the Free State, \\ Bloemfontein 9300, South Africa
}

(C) Società Italiana di Fisica and Springer-Verlag GmbH Germany, part of Springer Nature 2021

\section{Retraction to: Eur. Phys. J. Plus (2016) 131:373 \\ https://doi.org/10.1140/ep.jp/i2016-16373-2}

The Editor-in-Chief retracted this article [1] upon request of the Author. Following an investigation into the mathematical definitions contained in Section 2, the mathematical validity of the results (especially Theorem 1) contained in Section 3, and the physical applications presented in Section 6, the article was found to contain errors.

Author Abdon Atangana agrees to this retraction.

\section{Reference}

1. A. Atangana, Derivative with two fractional orders: A new avenue of investigation toward revolution in fractional calculus. Eur. Phys. J. Plus 131, 373 (2016). https://doi.org/10.1140/epjp/i2016-16373-2

The original article can be found online at https://doi.org/10.1140/epjp/i2016-16373-2.

\footnotetext{
a e-mail: AtanganaA@ufs.ac.za (corresponding author)
} 